\title{
Oxidation of Chalcones by Morpholinium Chlorochromate with Oxalic Acid as Catalyst: Kinetic and Mechanistic Study
}

\author{
K. Rajalakshmi ${ }^{1}$ and T. Ramachandramoorthy ${ }^{2}$ \\ ${ }^{1}$ Department of Chemistry, CARE School of Engineering, Tiruchirappalli 620 00, India \\ ${ }^{2}$ PG and Research Department of Chemistry, Bishop Heber College (Autonomous), Tiruchirappalli 620 017, India \\ Correspondence should be addressed to K. Rajalakshmi; chemraji8021@gmail.com
}

Received 3 February 2012; Revised 25 August 2012; Accepted 31 August 2012

Academic Editor: Angela Cardinali

Copyright ( 2013 K. Rajalakshmi and T. Ramachandramoorthy. This is an open access article distributed under the Creative Commons Attribution License, which permits unrestricted use, distribution, and reproduction in any medium, provided the original work is properly cited.

\begin{abstract}
The kinetics of oxidation of chalcones by morpholinium chlorochromate (MCC) has been studied in 55\% acetic acid-water (v/v) medium. The reaction showed unit order dependence each with respect to oxidant and catalyst and fractional order with respect to substrate and $\mathrm{H}^{+}$ion. Increased ionic strength has no effect on the reaction rate. In the case of substituted chalcones, the order with respect to substrate varies depending upon the nature of the substituent present in the ring. In general, the electron withdrawing substituents retard the reaction rate while the electron releasing substituents enhance the rate of the reaction. From the kinetic data obtained, the activation parameters have been calculated and a suitable mechanism has been proposed.
\end{abstract}

\section{Introduction}

Chalcones are oxidized by different oxidizing agents, and in all these reactions either the $>\mathrm{C}=\mathrm{C}<$ or the $>\mathrm{C}=\mathrm{O}$ group of the chalcone is attacked by the oxidant [1-5]. Chalcones either natural or synthetic are known to exhibit various biological activities $[6,7]$.

Halochromates have been used as mild and selective oxidizing reagents in synthetic organic chemistry. MCC is also one such reagent; only a few reports on the kinetics and mechanistic aspects of oxidation reactions by MCC are available in the literature [8-10]. In this paper, the kinetics of the oxidation of chalcones by MCC and mechanistic aspects have also been discussed.

\section{Experimental}

Chalcones were prepared by standard methods [11], and their melting points were checked with the literature values. All other chemicals used were of analytical reagent grade. MCC was also prepared by the reported method [12]. Solvents were purified by the usual procedure [13].

2.1. Kinetic Measurements. The reactions were carried out under pseudo-first-order conditions by maintaining always the substrate concentration in excess over that of MCC. All the reactions were carried out in black-coated vessels to avoid the possible photochemical reactions, if any. Known volumes of substrate, water, and acetic acid were mixed to bring the percentage of acetic acid to the desired value and thermostated. The reaction was started by adding the oxidant to the mixture and the aliquots were removed at definite time intervals, and the unreacted MCC was estimated by standard iodometric titrations.

2.2. Stoichiometry and Product Analysis. The stoichiometric runs were carried out in the presence of excess MCC which reveals that one mole of the oxidant consumes one mole of the substrate confirming the stoichiometry of the reaction as $1: 1$. 


$$
\begin{aligned}
& \mathrm{H}^{+}+\mathrm{HCrO}_{4}^{-} \stackrel{\mathrm{K}_{1}}{\rightleftharpoons} \mathrm{H}_{2} \mathrm{CrO}_{4} \\
& \mathrm{H}_{2} \mathrm{CrO}_{4}+\underset{\mathrm{COOH}}{\mathrm{COOH}} \stackrel{\mathrm{K}_{2}}{\longrightarrow} \mathrm{C}_{2}
\end{aligned}
$$

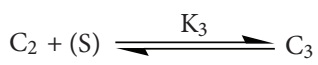

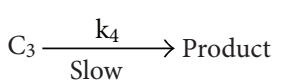

$$
\begin{aligned}
& {\left[\left.\left.\right|_{\mathrm{O}} ^{\mathrm{C}}\right|_{\mathrm{O}} ^{\mathrm{O}}\right.} \\
& \overbrace{\mathrm{O}}^{\mathrm{C}} \mathrm{C}^{\mathrm{C}} \mathrm{C}^{\prime}+\mathrm{Cr}(\mathrm{III}) \\
& \text { Rate }=\mathrm{k}_{4}\left[\mathrm{C}_{3}\right] \\
& =\frac{\mathrm{K}_{3} \mathrm{k}_{4}[\mathrm{~S}]\left[\mathrm{C}_{2}\right]}{\left\{1+\mathrm{K}_{3}[\mathrm{~S}]\right\}}=\frac{\mathrm{K}_{2} \mathrm{~K}_{3} \mathrm{k}_{4}[\mathrm{~S}][\mathrm{Cr}(\mathrm{VI})]\left[\mathrm{C}_{2}\right][\mathrm{ox}]}{\left\{1+\mathrm{K}_{3}[\mathrm{~S}]\right\}} \\
& =\frac{\mathrm{K}_{1} \mathrm{~K}_{2} \mathrm{~K}_{3} \mathrm{k}_{4}[\mathrm{~S}][\mathrm{ox}][\mathrm{Cr}(\mathrm{VI})]\left[\mathrm{H}^{+}\right]}{\left\{1+\mathrm{K}_{3}[\mathrm{~S}]\right\}\left\{1+\mathrm{K}_{1}\left[\mathrm{H}^{+}\right]\right\}} \\
& =\frac{\mathrm{K}_{1} \mathrm{~K}_{2} \mathrm{~K}_{3} \mathrm{k}_{4}[\mathrm{~S}][\mathrm{ox}][\mathrm{Cr}(\mathrm{VI})]\left[\mathrm{H}^{+}\right]}{\left\{1+\mathrm{K}_{3}[\mathrm{~S}] \mathrm{K}_{1}\left[\mathrm{H}^{+}\right]+\mathrm{K}_{3}[\mathrm{~S}]+\mathrm{K}_{1}\left[\mathrm{H}^{+}\right]\right\}} \\
& =\frac{\mathrm{K}_{1} \mathrm{~K}_{2} \mathrm{~K}_{3} \mathrm{k}_{4}[\mathrm{~S}][\mathrm{ox}][\mathrm{Cr}(\mathrm{VI})]\left[\mathrm{H}^{+}\right]}{1+\mathrm{K}_{1}\left[\mathrm{H}^{+}\right]+\mathrm{K}_{3}[\mathrm{~S}]} \\
& k_{\mathrm{obs}}=\frac{\mathrm{K}_{1} \mathrm{~K}_{2} \mathrm{~K}_{3} \mathrm{k}_{4}[\mathrm{~S}][\mathrm{ox}][\mathrm{Cr}(\mathrm{VI})]\left[\mathrm{H}^{+}\right]}{\left\{1+\mathrm{K}_{1}\left[\mathrm{H}^{+}\right]+\mathrm{K}_{3}[\mathrm{~S}]\right\}}
\end{aligned}
$$

SCHEME 1

TABLE 1: Rate constant for the different concentrations of MCC and chalcone at $313 \mathrm{~K}$.

\begin{tabular}{lcc}
\hline $\begin{array}{l}{[\mathrm{MCC}] \times 10^{3}} \\
\mathrm{~mol} \mathrm{dm}^{-3}\end{array}$ & $\begin{array}{c}\text { Chalcone] } \times 10^{2} \\
\mathrm{~mol} \mathrm{dm}^{-3}\end{array}$ & $\begin{array}{c}k_{\mathrm{obs}} \times 10^{4} \\
\mathrm{~s}^{-1}\end{array}$ \\
\hline 0.50 & 1.00 & 4.54 \\
1.00 & 1.00 & 4.52 \\
1.50 & 1.00 & 4.55 \\
2.00 & 1.00 & 4.53 \\
2.50 & 1.00 & 4.51 \\
1.50 & 0.50 & 3.71 \\
1.50 & 1.00 & 4.54 \\
1.50 & 1.50 & 5.45 \\
1.50 & 2.00 & 5.98 \\
1.50 & 2.50 & 6.49 \\
\hline
\end{tabular}

$\left[\mathrm{H}^{+}\right]=7.00 \times 10^{-2} \mathrm{~mol} \mathrm{dm}^{-3}, 55 \%$ acetic acid-water $(\mathrm{v} / \mathrm{v})$.

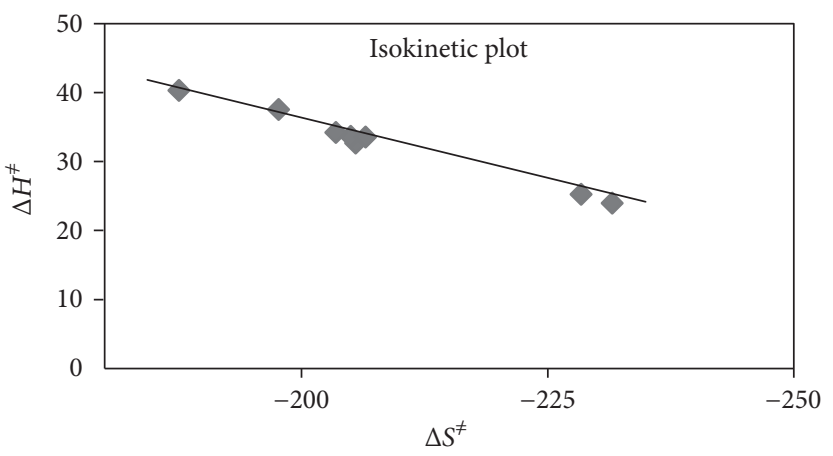

Figure 1: The plot of $\Delta H^{\neq}$versus $\Delta S^{\neq}$.

The reaction mixture from actual kinetic runs with excess of oxidant after slight warming was kept for two days and 
TABLE 2: Effect of catalyst, acidity, and solvent composition on the reaction rate at $313 \mathrm{~K}$.

\begin{tabular}{|c|c|c|c|c|c|}
\hline $\begin{array}{l}\text { Catalyst }] \times 10^{3} \\
\left(\mathrm{~mol} \mathrm{dm}^{-3}\right)\end{array}$ & $\begin{array}{c}k_{\mathrm{obs}} \times 10^{4} \\
\left(\mathrm{~s}^{-1}\right)\end{array}$ & $\begin{array}{l}{\left[\mathrm{H}^{+}\right] \times 10^{2}} \\
\left(\mathrm{~mol} \mathrm{dm}^{-3}\right) \\
\end{array}$ & $\begin{array}{c}k_{\mathrm{obs}} \times 10^{4} \\
\left(\mathrm{~s}^{-1}\right)\end{array}$ & $\begin{array}{c}\% \text { of acetic acid } \\
(\mathrm{v} / \mathrm{v})\end{array}$ & $\begin{array}{c}k_{\mathrm{obs}} \times 10^{4} \\
\left(\mathrm{~s}^{-1}\right)\end{array}$ \\
\hline 1.50 & 2.68 & 3.50 & 2.99 & 50 & 3.98 \\
\hline 3.00 & 3.58 & 5.25 & 3.73 & 55 & 4.54 \\
\hline 4.50 & 4.54 & 7.00 & 4.54 & 60 & 5.01 \\
\hline 6.00 & 5.59 & 8.75 & 5.12 & 65 & 5.32 \\
\hline 7.50 & 6.50 & 10.25 & 5.99 & 70 & 5.74 \\
\hline
\end{tabular}

$[\mathrm{MCC}]=1.50 \times 10^{-3} \mathrm{~mol} \mathrm{dm}^{-3},[$ substrate $]=1.00 \times 10^{-2} \mathrm{~mol} \mathrm{dm}^{-3}$.

TABLE 3: Effect of [acrylonitrile], $\left[\mathrm{Mn}^{2+}\right]$, and $\left[\mathrm{Al}^{3+}\right]$ on the reaction rate at $313 \mathrm{~K}$.

\begin{tabular}{|c|c|c|c|c|c|}
\hline $\begin{array}{l}\text { [acrylonitrile] } \times 10^{3} \\
\left(\mathrm{~mol} \mathrm{dm}^{-3}\right)\end{array}$ & $\begin{array}{c}k_{\mathrm{obs}} \times 10^{4} \\
\left(\mathrm{~s}^{-1}\right)\end{array}$ & $\begin{array}{c}{\left[\mathrm{Mn}^{2+}\right] \times 10^{3}} \\
\left(\mathrm{~mol} \mathrm{dm}^{-3}\right)\end{array}$ & $\begin{array}{c}k_{\mathrm{obs}} \times 10^{4} \\
\left(\mathrm{~s}^{-1}\right)\end{array}$ & $\begin{array}{l}{\left[\mathrm{Al}^{3+}\right] \times 10^{3}} \\
\left(\mathrm{~mol} \mathrm{dm}^{-3}\right)\end{array}$ & $\begin{array}{c}k_{\mathrm{obs}} \times 10^{4} \\
\left(\mathrm{~s}^{-1}\right)\end{array}$ \\
\hline 0 & 4.54 & 0 & 4.54 & 0 & 4.54 \\
\hline 0.50 & 4.51 & 0.50 & 4.19 & 0.50 & 4.62 \\
\hline 1.00 & 4.53 & 1.00 & 3.82 & 1.00 & 4.92 \\
\hline 1.50 & 4.50 & 1.50 & 3.54 & 1.50 & 5.23 \\
\hline 2.00 & 4.52 & 2.00 & 3.81 & 2.00 & 5.53 \\
\hline
\end{tabular}

$[\mathrm{MCC}]=1.50 \times 10^{-3} \mathrm{~mol} \mathrm{dm}^{-3},\left[\mathrm{H}^{+}\right]=7.00 \times 10^{-2} \mathrm{~mol} \mathrm{dm}^{-3}$.

[Chalcone $]=1.00 \times 10^{-2} \mathrm{~mol} \mathrm{dm}^{-3}, 55 \%$ acetic acid-water $(\mathrm{v} / \mathrm{v})$.

extracted with chloroform and dried over anhydrous sodium sulphate. The chloroform layer was then evaporated, and the solid product on analysis through UV and IR spectra $(\mathrm{KBr}$ pellet) technique was found to be epoxide.

\section{Results and Discussion}

The reaction was found to be first order with respect to the oxidant as evidenced by a good linearity in the plot of $\log [\mathrm{MCC}]$ versus time $(r=0.998)$. The pseudo-first-order rate constants were found to be independent of the initial concentration of MCC (Table 1).

At constant $[\mathrm{MCC}]$, the rate constants increased with increase in the concentration of the substrate. A plot of $\log k_{\text {obs }}$ versus $\log$ [substrate] gave a straight line with a slope of $0.35(r=0.998)$ (Table 1$)$.

The rates were found to increase with increase in the concentration of catalyst. The plot of $\log k_{\text {obs }}$ versus $\log$ [catalyst] gave a straight line with a slope of unity $(r=0.997)$. The effect of acidity was studied by varying the concentration of perchloric acid and the rate constants were found to increase with increase in the concentration of perchloric acid (Table 2 ). The plot of $\log k_{\text {obs }}$ versus $\log \left[\mathrm{H}^{+}\right]$gave a straight line with a slope of $0.49(r=0.991)$.

The rates were found to increase with the increase in the percentage of acetic acid, that is, with decrease in dielectric constant of the medium (Table 2). The enhanced oxidizing ability is attributed to the formation of acetochromate ion. The acetyl group enhanced the electron accepting power of chromium thereby facilitating the reaction. The reaction mixture when allowed to stand with acrylonitrile did not induce polymerization suggesting the absence of free radical pathway. The added $\mathrm{Mn}^{2+}$ ions have retarded the rate of the reaction [14] (Table 3). The addition of $\mathrm{Al}^{3+}$ did not affect the oxidation rate due to the formation of complex between $\mathrm{Al}^{3+}$ ion and oxalic acid. Based on the above observations, the mechanism and rate law was proposed (Scheme 1).

3.1. Mechanism and Rate Law. From the above observations, it is clear that the reaction is showing first-order dependence with respect to oxidant and catalyst and fractional order with respect to substrate and $\left[\mathrm{H}^{+}\right]$ion.

The oxidation by $\mathrm{Cr}(\mathrm{VI})$ will vary with the nature of the $\mathrm{Cr}(\mathrm{VI})$ species used, and the solvent will play an important role on the rate of the reaction. In aqueous solution and in the absence of other ions, the following equilibria are existing

$$
\begin{gathered}
\mathrm{H}_{2} \mathrm{CrO}_{4} \rightleftharpoons \mathrm{H}^{+}+\mathrm{HCrO}_{4}^{-} \quad \mathrm{K}_{1}=1.21 \mathrm{~mol} \mathrm{dm}^{-3}, \\
\mathrm{HCrO}_{4}{ }^{-} \rightleftharpoons \mathrm{H}^{+}+\mathrm{CrO}_{4}^{2-} \quad \mathrm{K}_{2}=3.0 \times 10^{-2} \mathrm{~mol} \mathrm{dm}^{-3}, \\
2 \mathrm{HCrO}_{4}^{-} \rightleftharpoons \mathrm{Cr}_{2} \mathrm{O}_{7}^{2-}+\mathrm{H}_{2} \mathrm{O} \quad \mathrm{K}_{3}=35.5
\end{gathered}
$$

Here the dimerization equilibrium is of considerable importance. In water, the dichromate ion will be predominating species only at the concentration of $\mathrm{Cr}(\mathrm{VI})$ is greater than about $0.05 \mathrm{~mol} \mathrm{dm}{ }^{-3}$. In this case, as the concentration of $\mathrm{Cr}(\mathrm{VI})$ is less than $0.05 \mathrm{~mol} \mathrm{dm}^{-3}$, monomeric form predominates and the active oxidizing species is $\mathrm{HCrO}_{4}$.

3.2. Effect of Substituents on Reaction Rate. The rate constant $k_{1}$ was estimated for the substituted chalcones at four different temperatures, namely, 303, 313, 323, and $333 \mathrm{~K}$, in order to calculate the thermodynamic parameters. The thermodynamic parameters were calculated using Eyring's plot [15], and the values are given in Table 5. The enthalpy of activation values are very low indicating a concerted 
TABLE 4: Effect of substituent on temperature.

\begin{tabular}{|c|c|c|c|c|c|c|c|c|c|}
\hline \multirow{2}{*}{ Substituents } & \multirow{2}{*}{ Order } & \multicolumn{4}{|c|}{$k_{1} \times 10^{4} \mathrm{~s}^{-1}$} & \multirow{2}{*}{$\begin{array}{c}\Delta H^{\neq} \\
\mathrm{kJ} \mathrm{mol}^{-1}\end{array}$} & \multirow{2}{*}{$\begin{array}{c}-\Delta S^{\ddagger} \\
\mathrm{JK}^{-1} \mathrm{~mol}^{-1}\end{array}$} & \multirow{2}{*}{$\begin{array}{c}\Delta G^{\neq} \\
\mathrm{kJ} \mathrm{mol}^{-1} \text { at } \\
313 \mathrm{~K}\end{array}$} & \multirow{2}{*}{$r$} \\
\hline & & $303 \mathrm{~K}$ & $313 \mathrm{~K}$ & $323 \mathrm{~K}$ & $333 \mathrm{~K}$ & & & & \\
\hline Parent-H & 0.42 & 2.62 & 4.54 & 6.48 & 9.53 & 32.67 & 205.54 & 97.00 & 0.994 \\
\hline$p-\mathrm{OCH}_{3}$ & 0.38 & 5.08 & 6.42 & 8.65 & 10.10 & 17.09 & 251.79 & 95.90 & 0.992 \\
\hline$p-\mathrm{CH}_{3}$ & 0.44 & 3.70 & 5.49 & 7.57 & 9.64 & 23.95 & 231.58 & 96.43 & 0.993 \\
\hline$m-\mathrm{CH}_{3}$ & 0.52 & 3.35 & 4.85 & 6.75 & 9.15 & 25.21 & 228.42 & 96.71 & 0.999 \\
\hline$p-\mathrm{Br}$ & 0.26 & 1.90 & 3.37 & 4.99 & 7.12 & 33.61 & 205.04 & 97.79 & 0.992 \\
\hline$p-\mathrm{Cl}$ & 0.28 & 1.79 & 3.23 & 4.72 & 6.90 & 34.21 & 203.54 & 97.92 & 0.992 \\
\hline$m-\mathrm{Cl}$ & 0.34 & 1.42 & 2.74 & 3.81 & 6.75 & 33.53 & 206.54 & 98.18 & 0.993 \\
\hline$m-\mathrm{NO}_{2}$ & 0.40 & 0.58 & 1.93 & 2.94 & 5.83 & 40.30 & 187.57 & 99.01 & 0.993 \\
\hline$p-\mathrm{NO}_{2}$ & 0.45 & 0.54 & & 2.58 & 4.61 & 37.50 & 197.72 & 99.39 & 0.997 \\
\hline
\end{tabular}

TABLE 5: Reaction constant for the oxidation of substituted anilines.

\begin{tabular}{lcc}
\hline Temperature & $\rho$ & $r$ \\
\hline K & -0.92 & 0.996 \\
313 & -0.54 & 0.998 \\
323 & -0.49 & 0.996 \\
333 & -0.33 & 0.996 \\
\hline
\end{tabular}

mechanism as proposed. The negative values of the entropies of activation $\left(\Delta S^{\neq}\right)$suggested that the transition state formed is considerably more rigid than initial states. The constancy of the $\Delta G^{\neq}$values indicated a common mechanism for the oxidation of all the substrates.

The entropy of activation and heat of reaction are correlated by

$$
\Delta H^{\neq}=\Delta H^{o}+\beta \Delta S^{\neq}
$$

where $\beta$ is the isokinetic temperature. A plot of $\Delta H^{\neq}$versus $\Delta S^{\neq}$gave a straight line with good correlation coefficient $(r=$ 0.997) (Figure 1). The isokinetic temperature for the reactions between chalcones and MCC in aqueous acetic acid is $365 \mathrm{~K}$, which is greater than the experimental temperature.

The linear relationship in the Exner plot $[16,17]$ at 3 $+\log k_{313 \mathrm{~K}}$ versus $3+\log k_{303 \mathrm{~K}}$ observed in the present study also supports the conclusion drawn from the isokinetic temperature.

To have an idea about the order with respect to each of the substrate has been studied at $313 \mathrm{~K}$, and results are given in Table 4. It is interesting to note that all the substituted chalcones showed a fractional order dependence on the reaction rate. The electron releasing groups enhanced and the electron withdrawing groups retarded the reaction rate.

If this linearity between enthalpies and entropies is true, it should predict a meaningful correlation between $\log k_{\text {obs }}$ and $\sigma$. When the Hammett equation [18] was applied to this reaction system with the usual substituent constants, $\sigma$, excellent linear correlation was obtained with negative $\rho$ values, which indicates that the electron releasing substituents accelerate and the electron withdrawing substituents retard the rate of the reaction. The negative sign of rho values (Table 5) indicates that electron deficient transition state is involved in the mechanism of oxidation.

\section{Conclusion}

In this paper we have reported the detailed mechanism of oxidation of chalcones and some para- and meta-substituted chalcones by MCC. The reaction is first order with [oxidant] and [catalyst] and fractional order with [chalcones] and $\left[\mathrm{H}^{+}\right]$. The oxidation of chalcones yields the corresponding epoxides. The negative value of $\Delta S^{f}$ provided support for the formation of the activated complex in the slow step. The order of reactivities with substituents is $p-\mathrm{OCH}_{3}>p-\mathrm{CH}_{3}>m$ $\mathrm{CH}_{3}>\mathrm{H}>p-\mathrm{Br}>p-\mathrm{Cl}>m-\mathrm{Cl}>m-\mathrm{NO}_{2}>p-\mathrm{NO}_{2}$. The constancy of $\Delta G^{\neq}$values indicated that all the substituted chalcones are operative in the same mechanism.

\section{Acknowledgments}

The authors thank the Principal and the Management of Bishop Heber College (autonomous), Tiruchirappalli, for providing laboratory facilities.

\section{References}

[1] J. A. Kumar and S. Sondu, "Kinetics and mechanism of oxidation of chalcones by trichloroisocyanuric acid [TCICA] in $\mathrm{HOAc}^{-} \mathrm{HCIO}_{4}$ medium," Indian Journal of Chemistry-Section $A$, vol. 46, no. 11, pp. 1792-1795, 2007.

[2] M. Komal Reddy, N. Bhasker, and K. Raghava Raju, Rasayan Journal of Chemistry, vol. 2, no. 1, p. 108, 2009.

[3] N. C. Khanduwal, K. K. Satapathy, and P. L. Nayak, Journal of the Chemical Society, p. 328, 1974.

[4] A. K. Patnaik, P. L. Nayak, and M. K. Rout, Indian Journal of Chemistry, vol. 8, p. 722, 1970.

[5] S. Sondu, B. Sethuram, and T. Navaneeth Rao, Oxidn Commun, vol. 10, p. 167, 1987.

[6] Y. R. Prasad, P. P. Kumar, P. R. Kumar, and A. S. Rao, "Synthesis and antimicrobial activity of some new chalcones of 2-acetyl 
pyridine," E-Journal of Chemistry, vol. 5, no. 1, pp. 144-148, 2008.

[7] S. Mukherjee, V. Kumar, A. K. Prasad et al., "Synthetic and biological activity evaluation studies on novel 1,3diarylpropenones," Bioorganic and Medicinal Chemistry, vol. 9, no. 2, pp. 337-345, 2001.

[8] A. Choudhary, N. Malani, S. Agarwal, M. Sharma, and V. Sharma, "Correlation analysis of reactivity in the oxidation of substituted benzaldehydes by morpholinium chlorochromate," Journal of the Indian Chemical Society, vol. 86, no. 9, pp. 927-935, 2009.

[9] P. K. Sharma, N. Malini, and M. Baghmar, International Journal of Chemical Kinetics, vol. 41, p. 65, 2009.

[10] N. Malani, S. Pohani, M. Baghmar, and P. K. Sharma, "Kinetics and mechanism of oxidation of some thioacids by morpholinium chlorochromate," Indian Journal of Chemistry-Section A, vol. 47, no. 9, pp. 1373-1376, 2008.

[11] B. S. Furniss, A. J. Hannaford, P. W. G. Smith, and A. R. Tatchell, Textbook of Practical Organic Chemistry, Essex, Longman, UK, 5th edition, 1989.

[12] H. N. Sheikh, M. Sharma, A. Hussain, and B. L. Kalsotra, "Morpholinium chlorochromate-a new reagent for oxidation of alcohols," Oxidation Communications, vol. 28, no. 4, pp. 887-893, 2005.

[13] K. J. P. Orton and A. E. Bradfield, "The chlorination of anilides. The directing influence of the acylamido-group," Journal of the Chemical Society, pp. 986-997, 1927.

[14] P. V. Subba Rao, Indian Journal of Chemistry, vol. 30A, p. 239, 1991.

[15] O. Exner, "Concerning the isokinetic relationship," Nature, vol. 201, no. 4918, pp. 488-490, 1964.

[16] O. Exner, R. W. Streitwiser, and R. W. Talt, Progress in Physical Organic Chemistry, vol. 41, 1973.

[17] H. Eyring, Journal of Chemical Physics, vol. 33, p. 107, 1935.

[18] J. Shorter, Correlation Analysis in Organic Chemistry, Clarandon Press, Oxford, UK, 1972. 

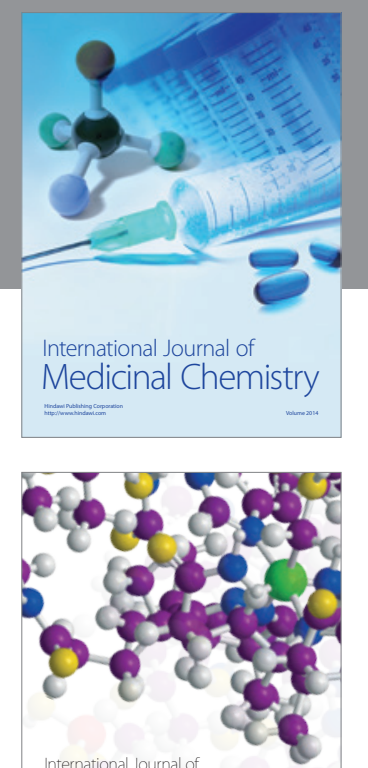

\section{Carbohydrate} Chemistry

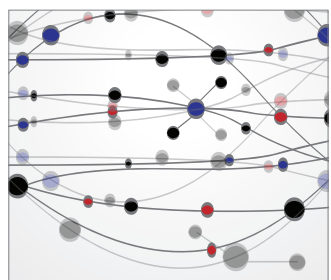

The Scientific World Journal
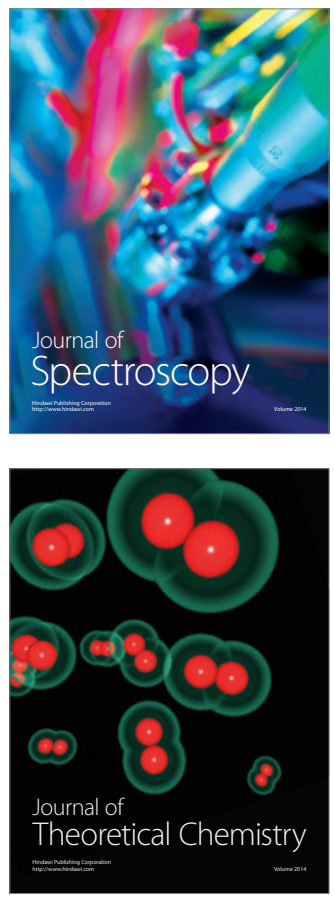
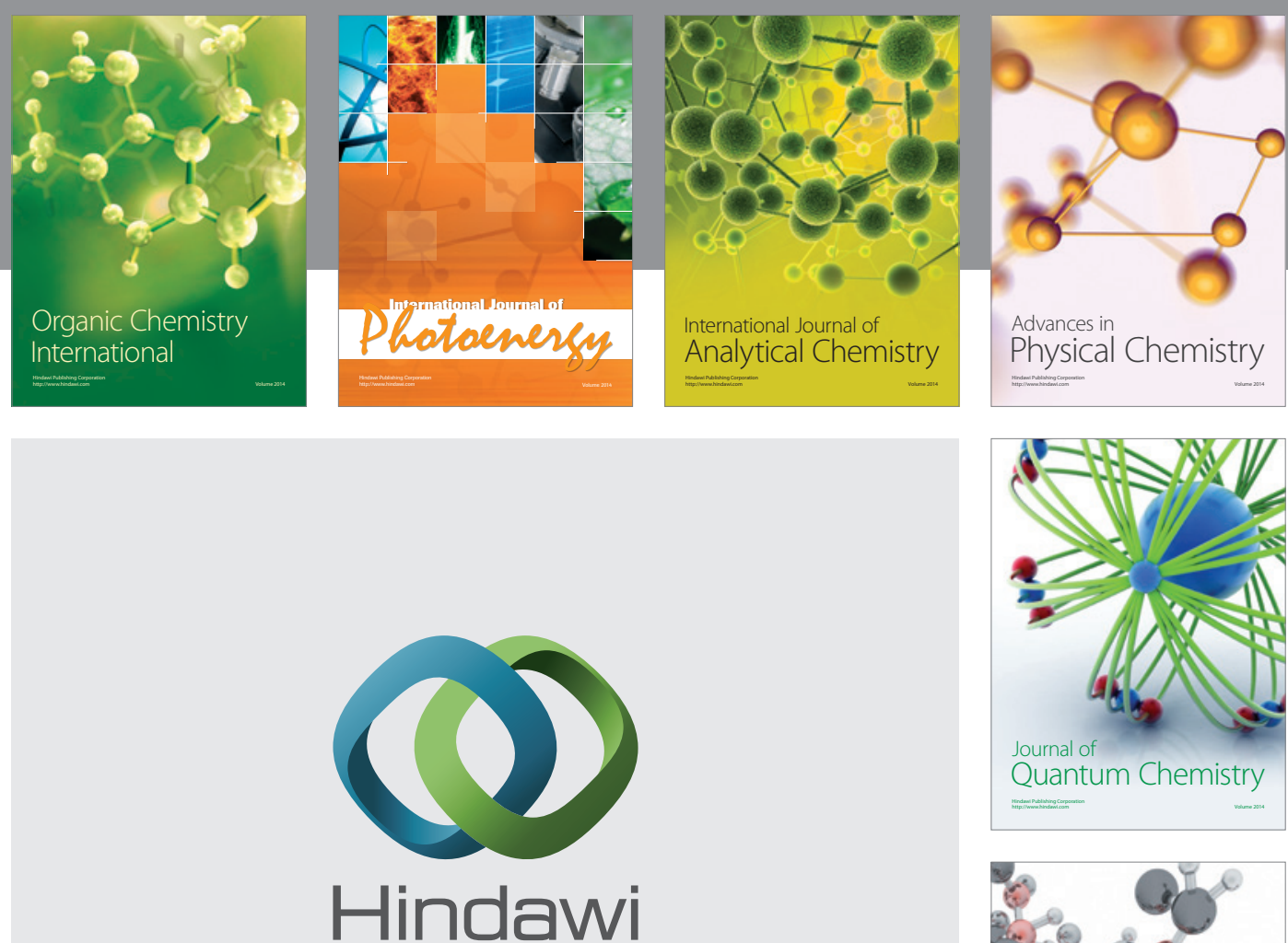

Submit your manuscripts at

http://www.hindawi.com

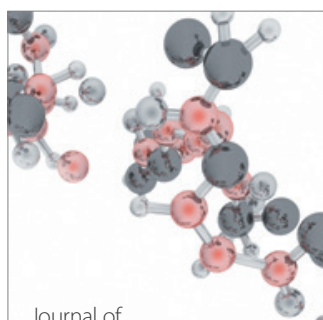

Analytical Methods

in Chemistry

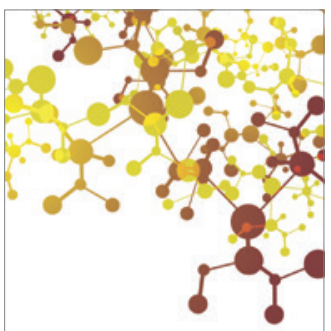

Journal of

Applied Chemistry

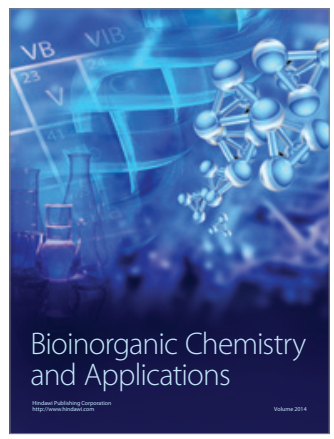

Inorganic Chemistry
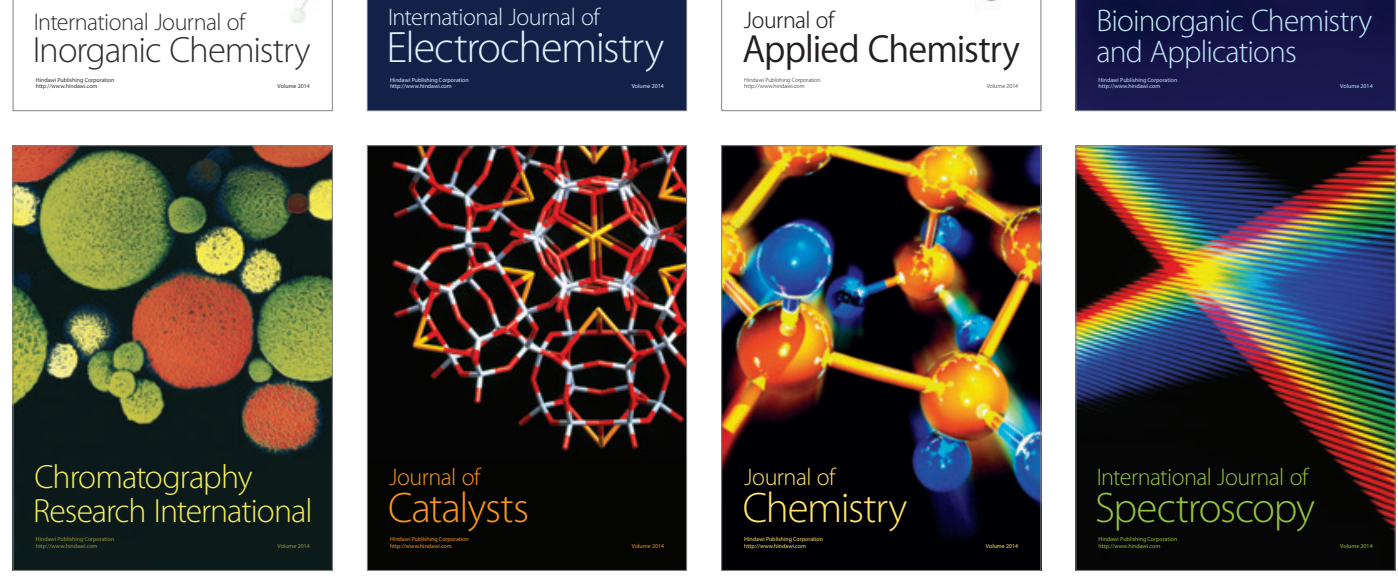